the MCQ papers. An examination of this kind does not lend itself to quick decisions. Furthermore, in present conditions 'moderation' of the marks of examinations is seen as desirable to achieve as high a degree of uniformity in the assessment of all candidates as possible. Careful assessment of the marks by a central committee is especially important in our examination where the number of attempts by each candidate is limited.

Some of the difficulties we have in conducting the examinations is illustrated by the example given in Dr Sen's letter, of variations in the approach of different examiners. We hold meetings of new examiners and annual meetings of all examiners partly to assist in providing an assessment of candidates which covers certain key areas of knowledge and practice. However, clinical cases vary widely and we are ultimately dependent upon the judgement of our examiners in assessing a candidate's competence. In the course of the examination the work of candidates is assessed by a series of examiners who each act independently. The Examinations Sub-Committee of the Court of Electors sees all the marks of every candidate anonymously before deciding who shall pass the examination. Only after decisions have been reached on all candidates are the names identifiable by the Sub-Committee.

The examinations for the MRCPsych are bound to remain stressful in some measure; I can only reassure candidates that the College will make the arrangements for the examinations as fair as we possibly can.

R. H. S. Mindham, Chief Examiner, Royal College of Psychiatrists

How to change prescribing of hypnotics

Sir: Drs Harborne \& Tudor's audit study shows how change can come about through the medical audit practice (Psychiatric Bulletin. March 1995, 19, 155-157). We found their paper extremely useful as we have recently tried and failed to recommend a change in prescribing habits of hypnotics.

We initially surveyed a psychiatric in-patient population in May 1994; of the total of 111 inpatients, $36(33 \%)$ were receiving night sedation. The prescribed medications were temazepam for 28 patients $(78 \%)$ of total prescriptions, chloral hydrate for five (14\%) and nitrazepam for three patients $(8 \%)$. The retrospective examination of psychiatric discharge summaries showed $32 \%$ discharged on night sedation (only nine $(2.5 \%)$ of the 414 summaries had no information of the medication on discharge).

To attempt to change prescribing habits we devised a night sedation policy:

(a) non-drug treatment based on behaviour approach (explanation of insomnia, avoid stimulants, regular eating patterns, exercise, hot milk drink, no daytime naps)

(b) neuroleptic medication, give at night where possible

(c) if prescription is necessary, use p.r.n., after $11 \mathrm{pm}$, alternate days where possible

(d) drugs of choice: chloral hydrate, temazepam, chlormethiazole and nitrazepam

(e) no hypnotics if the patient is on leave

(f) only one week's supply on discharge.

We met with clinical colleagues and nursing staff, discussed the policy, and presented findings of the initial survey.

At follow-up nine months later, in January 1995, there was no change in night sedation prescriptions, either during in-patient stay or at discharge. In addition to the medical staff failing to follow the recommended guidelines, the night nursing staff also found it difficult to resist some patients requesting the night sedation on a regular basis. We found problems with some patients who did not comply with the recommended behavioural techniques. Finally, we would add that it was relatively easy for us to detect hospitalproduced night sedation dependency in contrast to Harborne \& Tudor who comment how difficult it was for them to do. We used our comprehensive psychiatric discharge summaries which list medication on admission and discharge.

RAFAEL LOPEZ and JOAN RUTHERFORD Heathlands Mental Health NHS Trust, Ridgewood Centre, Old Bisley Road, Camberley GU16 5QE

\section{Racism in psychiatric units}

Sir: I read with interest 'Sexual harassment of staff by patients in mental health units' by Maria B. Tomé de la Granja (Psychiatric Bulletin. March 1995, 19, 168-169). Not only is sexual harassment a recurring aspect of 